\title{
EDITORIAL
}

\section{FRAILTY AND POLYPHARMACY}

\author{
Y. ROLLAND ${ }^{1}$, J.E. MORLEY ${ }^{2}$
}

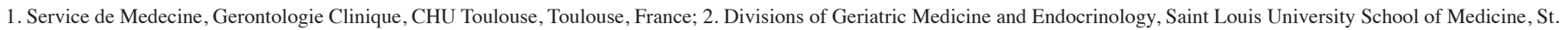
Louis, Missouri, USA. Corresponding author: John E. Morley, MB, BCh, Division of Geriatric Medicine, Saint Louis University School of Medicine, 1402 S. Grand Blvd., M238, St. Louis, MO 63104,Email: morley@slu.edu

Frailty is now recognized as a major risk factor for future disability and mortality (1-3). The physical frailty phenotype as originally defined by Fried et al (4) has been simplified to be rapidly detected using either the FRAIL screen (5-7) or the Gerontopole Screening Questionnaire $(8,9)$. The FRAIL scale has been shown to have equivalent predictive ability to other more complex frailty scales $(10,11)$. Polypharmacy related to the increase in illnesses in older persons has been identified as one of the treatable components of the FRAIL scale (12). An alternative approach to defining frailty has been proposed by Rockwood (13). This scale consists of adding up all the deficits a person has and presenting the result as a percentage of all deficits measured. In actuality, this represents a co-morbidity index. Other frailty scales such as the Tilburg Frailty Indicator $(14,15)$ and the Groningen Frailty Index $(16,17)$ include both physical and psychosocial elements. Recently, a number of studies have suggested that the presence of a cognitive deficit leads to worse outcomes in persons with a physical frailty deficit (18-20).

It is now well recognized that polypharmacy in older persons leads to poor outcomes (21-24). Six cross-sectional studies have suggested that the presence of polypharmacy is significantly related to an increased propensity for older persons to have the physical frailty phenotype (25-30). These studies have suggested a reasonable cut-off for polypharmacy's relationship to frailty is more than 6 medicines.

There are numerous reasons why polypharmacy may lead to frailty (31). Anticholinergic (atropinic) drug exposure has been shown to be associated with frailty (32). In frail nursing home residents anticholinergic drugs are associated with increased functional decline, more falls and a greater incidence of dementia and delirium (33-35). Stopping anticholinergic drugs improves cognitive function $(36,37)$. Anticholinergics are also associated with hip fractures (38). Another study found that anticholinergic drugs decreased the ability to bathe, groom, dress, transfer and to be mobile, as well as increasing in-hospital mortality (39). It should be pointed out that one recent study showed that appropriate anticholinergic medication use may be relatively safe in hospitalized patients (40). Weight loss is common in older persons (41-43). Loss of fat results in more side effects from fat soluble drugs. In addition, persons with weight loss tend to have a decline in their blood pressure. Thus, older persons are often overtreated for hypertension by not having their antihypertensive medicines reduced $(44,45)$. Dehydration is common in older persons and is often made worse by inappropriate use of diuretics to treat pedal edema
(46). Dehydration is associated with frailty, falls, syncope, poor cognition, disability and mortality (47-51).

Changes in metabolism and clearance of drugs with aging increases the chances of drug toxicity and drug-drug interaction $(52,53)$. The decrease in L-thyroxine clearance with aging often results in excess L-thyroxine doses which lead to weight and muscle loss, osteoporosis and heart disease. The use of selective serotonin reuptake inhibitors (SSRIs), can lead to hyponatremia and delirium (54). Proton pump inhibitors (PPIs) are overused in older persons, leading to reduced vitamin B12 and calcium absorption and possibly bacterial overgrowth and clostridium difficile infections (55). In geriatric wards and nursing homes PPIs are associated with increased mortality (56). Overtreatment of persons with diabetes mellitus is associated with frailty (57-59). Overall, polypharmacy has been associated with a reduction in walking speed and gait strength, disability and mortality (60-64). Polypharmacy is also related to cognitive decline and delirium (65-67). Persons with cognitive decline have decreased self-management skills and this creates increased risks when they are on multiple medications (68). Reduction in polypharmacy leads to reduction in costs without creating any increase in harms $(1,69-71)$. We recommend that all frail older persons have their medications reviewed by a pharmacist with the ideal of reducing medications to 6 or less (72). While this may not be possible in every individual, we believe that it is possible in the majority of frail older persons. If no pharmacist, either the STOPP/START or Beers criteria can be used $(73,74)$. The "Fit for the Aged" (FORTA) is a system developed in Germany that appears to have some additional advantages in being easy to use in older persons (75). It also needs to be recognized that polypharmacy is a major cause of non-adherence to drug therapy (76).

\section{References}

1. Michel JP. Frailty: Successful clinical practice implementation. J Nutr Health Aging 2014;18:470.

. Morley JE. Frailty screening comes of age. J Nutr Health Aging 2014;18:453-454

3. Morley JE, Vellas B, van Kan GA, et al. Frailty consensus: A call to action. J Am Med Dir Assoc 2013;14:392-397.

4. Fried LP, Tangen CM, Walston J, et al. Frailty in older adults: Evidence for a phenotype. J Gerontol A Biol Sci Med Sci 2001;56:M146-M156.

5. Morley JE, Malmstrom TK, Miller Dk. A simple frailty questionnaire (FRAIL) predicts outcomes in middle aged African Americans. J Nutr Health Aging 2012;16:601-608.

6. Malmstrom TK, Miller DK, Morley JE. A comparison of four frailty models. J Am Geriatr Soc 2014;62:721-726.

7. Woo J, Leung J, Morley JE. Comparison of frailty indicators based on clinical phenotype and the multiple deficit approach in predicting mortality and physical limitation. J Am Geriatr Soc 2012;60:1478-1486.

8. Tavassoli N, Guyonnet S, Abellan van Kan G, et al. Description of 1,108 older patients referred by their physician to the "Geriatric Frailty Clinic (G.F.C) for assessment of frailty nd prevention od disability" at the Gerontopole. J Nutr Health Aging 2014;18:457-464. 


\section{FRAILTY AND POLYPHARMACY}

9. Vellas B, Balardy L, Gillette-Guyonnet S, et al. Looking for frailty in communitydwelling odler persons: The Gerontolpole frailty screening tool (GFST). J Nutr Health Aging 2013;17:629-631.

10. Theou $\mathrm{O}$, Brothers TD, Peña FG, et al. Identifying common characteristics of frailty across seven scales. J Am Geriatr Soc 2014;62:901-906.

11. Revindrarajah R, Lee DM, Pye SR, et al. The ability of three models of frailty to predict all-cause mortality: Results from the European Male Aging Study (EMAS). Arch Gerontol Geriatr 2013;57:360-368.

12. Morley JE. Frailty: A time for action. European Geriatr Med 2013;4:215-216.

13. Rockwood K, Abeysundera MJ, Mitnitski A. How should we grade frailty in nursing home patients? J Am Med Dir Assoc 2007;8:595-603.

14. Gobbens RJ, van Assen MA, Luijkx KG, et al. The Tilburg Frailty Indicator: Psychometric properties. J Am Med Dir Assoc 2010;11:344-355.

15. Gobbens RJ, Luijkx KG, Wijnen-Sponselee MT, Schols JM. Towards an integral conceptual model of frailty. J Nutr Health Aging 2010;14:175-181.

16. Hogendijk EO, van Hout HP. Investigating measurement properties of the Groningen Frailty Indicator: A more systematic approach is needed. J Am Med Dir Assoc 2012;13:757; Author reply 757-758.

17. Peters LL, Boter H, Buskens E, Slaets JP. Measurement properties of the Groningen Frailty Indicator in home-dwelling and institutionalized elderly people. J Am Med Dir Assoc 2012;13:546-551.

18. Woods AJ, Cohen RA, Pahor M. Cognitive frailty: Frontiers and challenges. J Nutr Health Aging 2013;17:741-743.

19. Malmstrom TK, Morley JE. Frailty and cognition: Linking two common syndromes in older persons. J Nutr Health Aging 2013;17:723-725.

20. Kelaiditi E, Cesari M, Canevelli M, et al. Cognitive frailty: Rational and definition from an (I.A.N.A./I.A.G.G.) international consensus group. J Nutr Health Aging 2013;17:726-734

21. Sganga F, Vetrano DL, Volpato S, et al. Physical performance measures and polypharmacy among hospitalized older adults: Results from the CRIME study. J Nutr Helath Aging 2014;18:616-621.

22. Tamura BK, Bell CL, Lubimir K, et al. Physician intervention for medication reduction in a nursing home: The polypharmacy outcomes project. J Am Med Dir Assoc 2011;12:326-330.

23. Bronskill SE, Gill SS, Paterson JM, et al. Exploring variation in rates of polypharmacy across long term care homes. J Am Med Dir Assoc 2012;13:309.e15-e21.

24. Fitzgerald SP, Bean NG. An analysis fo the interactions between individual comorbities and their treatments - implications for guidelines and polypharmacy. J Am Med Dir Assoc 2010;11:475-484.

25. Gnjidic D, Hilmer SN, Blyth Fm, et al. Polypharmacy cutoff and outcomes: Five or more medicines were used to identify community-dwelling older men at risk of different adverse outcomes. J Clin Epidemiol 2012;65:989-995.

26. Gnjidic D, Hilmer SN, blyth FM, et al. High-risk prescribing and incidence of frailty among older community-dwelling men. Clin Pharmacol Ther 2012;91:521-528.

27. Bennett A, Gnjidic D, Gillett M, et al. Prevalence and impact of fall-risk-increasing drugs, polypharmacy, and drug-drug interactions in robust versus frail hospitalized falls patients: A prospective cohort study. Drugs Aging 2014;31:225-232.

28. Woo J, Leung J. Multi-morbidity, dependency, and frailty singly or in combination have different impact on health outcomes. Age (Dordr) 2014;36:923-931.

29. Turner JP, Shakib S, Singhal N, et al. Prevalence and factors associated with polypharmacy in older people with cancer. Support Care Cancer 2014;22:1727-1734.

30. Moulis F, Moulis G, Balardy L, et al. Searching for a polypharmacy threshold associated with frailty. J Am Med Dir Assoc 2015:16:259-261.

31. Morley JE. Inappropriate drug prescribing and polypharmacy are major causes of poor outcomes in long-term care. J Am Med Dir Assoc 2014;15:780-782.

32. Moulis F, Moulis G, Balardy L, et al. Exposure to atropinic drugs and frailty status. J Am Med Dir Assoc 2015:16:253-257

33. Landi F, Del'Aquila G, Collamati A, et al. Anticholinergic drug use and negative outcomes among the frail elderly population living in a nursing home. J Am Med Dir Assoc 2014;15:825-829.

34. Morley JE. Anticholinergic medications and cognition. J Am Med Dir Assoc 2011;12:543543.e1.

35. Lowry E, Woodman RJ, Soiza RL, Mangoni AA. Associations between the anticholinergic risk scale score and physical function: Potential implications for adverse outcomes in older hospitalized patients. J Am Med Dir Assoc 2011;12:565-572.

36. Cruz-Oliver DM, Malmstrom TK, Roegner M, et al. Cognitive deficit reversal as shown by changes in the Veterans Affairs Saint Louis University Mental Status (SLUMS) examination scores 7.5 years later. J Am Med Dir Assoc 2014;15:687.e5-10.

37. Fox C, Richardson K, Maidment ID, et al. Anticholinergic medication use and cognitive impairment in the older population: The medical research council cognitive function and ageing study. J Am Geriatr Soc 2011;59:1477-1483.

38. Moga DC, Carnahan RM, Lund BC, et al. Risks and benefits of bladder antimuscarinics among elderly residents of Veterans Affairs Community Living Centers. J Am Med Dir Assoc 2013;14:749-760.

39. Lowry E, Woodman RJ, Soiza RL, Mangoni AA. Associations between the anticholinergic risk scale score and physical function: Potential implications for adverse outcomes in older hospitalized patients. J Am Med Dir Assoc 2011;12:565-572.

40. Narbey D, Jolly D, Mahmoudi R, et al. Relationship between anticholinergic drug use and one-year outcome among elderly people hospitalized in medical wards via emergency department: The SAFES cohort study. J Nutr Health Aging 2013;17:766-771.

41. Morley JE. Weight loss in older persons: New therapeutic approaches. Curr Pharm Des 2007; 13:3637-3647

42. Morley JE. Anorexia of aging: A true geriatric syndrome. J Nutr Health Aging 2012;16:422-425.
43. Rolland Y, Kim MJ, Gammack JK, et al. Office management of weight loss in older persons. Am J Med 2006;119:1019-1026.

44. van der Wardt V, Logan P, Conroy S, et al. Antiphypertensive treatment in people with dementia. J Am Med Dir Assoc 2014;15:620-629.

45. Morley JE. Treatment of hypertension in older persons: What is the evidence? Drugs Aging 2014;31:331-337.

46. Thomas DR, Cote TR, Lawhorne L, et al. Understanding clinical dehydration and its treatment. J Am Med Dir Assoc 2008;9:292-301.

47. Schols JM, De Groot CP, van der Cammen Tj, Olde Rikkert MG. Preventing and treating dehydration in the elderly during periods of illness and warm weather. J Nutr Health Aging 2009;13:150-157.

48. Wilson MM. The management of dehydration in the nursing home. J Nutr Health Aging 1999;3:53-61.

49. Shah MK, Workeneh B, Taffet GE. Hypernatremia in the geriatric population. Clin Interv Aging 2014;9:1987-1992.

50. Huang JJ, Sharda N, Riaz IB, Alpert JS. Summer syncope syndrome. Am J Med 2014;127:787-790.

51. Wilson MM, Morley JE. Impaired cognitive function and mental performance and mild dehydration. Eur J Clin Nutr 2003;57(Suppl 2):S24-S29.

52. Schmucker DL. Drug disposition in the elderly: A review of the critical factors. J Am Geriatr Soc 1984;32:144-149.

53. Hubbard RE, O'Mahony MS, Woodhouse KW. Medication prescribing in frail older people. Eur J Clin Pharmacol 2013;69:319-326.

54. Morley JE. Clinical practice in nursing homes as a key for progress. J Nutr Health Aging 2010; $14: 586-593$

55. De Souto Barreto P, Lapeyre-Mestre M, Mathieu C, et al. Prevalence and associations of the use of proton-pump inhibitors in nursing homes: A cross-sectional study. J Am Med Dir Assoc 2013;14:265-269.

56. Maggio M, Corsonello A, Ceda GP, et al. Proton pump inhibitors and risk of 1-year mortality and rehospitalization in older patients discharged from acute care hospitals. JAMA Intern med 2013;173:518-523.

57. Benetos A, Novella JL, Guerci B, et al. Pragmatic diabetes management in nursing homes: individual care plan. J Am Med Dir Assoc 2013;14:791-800.

58. Sinclair A, Morley JE. How to manage diabetes mellitus in older persons in the $21 \mathrm{st}$ century: Applying these principles to long term diabetes care. J Am Med Dir Assoc 2013; 14:777-780.

59. Sinclair A, Morley JE, Rodriguez-Mañas L, et al. Diabetes mellitus in older people: Position statement on behalf of the International Association of Gerontology and Geriatrics (IAGG), the European Diabetes Working Party for Older People (EDWPOP), and the International Task Force of Experts in Diabetes. J Am Med DIr Assoc 2012;13:497-502.

60. Husson N, Watfa G, Laurain MC, et al. Characteristics of polymedicated ( $>4$ ) elderly: A survey in a community-dwelling population aged 60 years and over. J Nutr Health Aging 2014;18:87-91.

61. Onder G, Liperoti R, Foebel A, et al. Polypharmacy and mortality among nursing home residents with advanced cognitive impairment: Results from the SHELTER study. J Am Med DIr Assoc 2013;14:450.e7-e12.

62. Takahashi PY, North F. Pilot study of inappropriate medications and balance: A study in a continuous care center. J Am Med Dir Assoc 2007;8:545.

63. Gokce Kutsal Y, Barak A, Atalay A, et al. Polypharmacy in the elderly: A multicenter study. J Am Med Dir Assoc 2009; 10:486-490.

64. Morley JE. Polypharmacy in the nursing home. J Am Med Dir Assoc 2009;10:289-291.

65. Hein C, Forgues A, Piau A, et al. Impact of polypharmacy on occurrence of delirium in elderly emergency patients. J Am Med Dir Assoc 2014;15:850.e11-e15.

66. Morley JE. Mild cognitive impairment - a treatable condition. J Am Med Dir Assoc 2014;15:1-5.

67. Alakkassery S, Flaherty JH. Delirium in the elderly. J Med Liban 2012;60:214-219.

68. Sino CG, Sietzema M, Egberts TC, Schuurmans MJ. Medication management capacity in relation to cognition and self-management skills in older people on polypharmacy. J Nutr Health Aging 2014;18:44-49.

69. Kojima G, Bell C, Tamura B, et al. Reducing cost by reducing polypharmacy: The polypharmacy outcomes project. J Am Med Dir Assoc 2012;13:818.e11-e15.

70. Cestac P, Tavassoli N, Vellas B, Rolland Y. Improving medication use in the nursing homes: A European perspective. J Am Med Dir Assoc 2013;14:6-9.

71. Little MO, Morley A. Reducing polypharmacy: Evidence from a simple quality improvement initiative. J Am Med Dir Assoc 2013;14:152-156.

72. De Souto Barreto P, Vellas B, Morley Je, Rolland Y. The nursing home population: An opportunity to make advances on research on multimorbidity and polypharmacy. J Nutr Health Aging 2013;17:399-400.

73. Grace AR, Briggs R, Kieran RE, et al. A comparison of Beers and STOPP criteria in assessing potentially inappropriate medications in nursing home residents attending the emergency department. J Am Med Dir Assoc 2014;15:830-834.

74. Lesende I, Martin C, Mendibil I, Lopez G. Potentiality of STOPP/START criteria used in primary care to effectively change inappropriate prescribing in elderly patients. European Geriatric Medicine 2013;4:293-298.

75. Michalek C, Wehling M, Schlitzer J, Frohnhofen H. Effects of "Fit fOR The Aged" (FORTA) on pharmacotherapy and clinical endpoints - a pilot randomized controlled study. Eur J Clin Pharmacol 2014;70:1261-1267.

76. Stegemann S, Baeyens JP, Ameta F, et al. Adherence measurement systems and technology for medications in older patient populations. European Geriatr Med 2012;3:254-260 